\title{
Steps toward a shared governance response for achieving Good Environmental Status in the Mediterranean Sea
}

\author{
$\underline{\text { Sergio Cinnirella }}^{1}, \underline{\text { Rafael Sardà }}^{2}, \underline{\text { Juan Luis Suárez de Vivero }}^{3}, \underline{\text { Ruth Brennan }}^{4}$, Alberto Barausse $^{5}, \underline{\text { John Icely }}^{6}, \underline{\text { Tiziana Luisetti }}^{7}$,

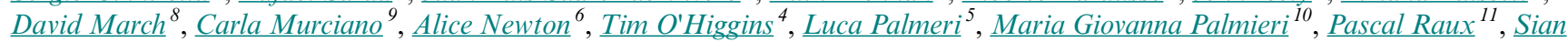 \\ $\underline{\text { Rees }}^{12}, \underline{\text { Joan Albaigés }}^{9}$, Nicola Pirrone $^{1}$ and Kerry Turner ${ }^{10}$
}

\begin{abstract}
The Mediterranean region is of fundamental importance to Europe given its strategic position. The responsibility for its overall ecosystem integrity is shared by European Union Member States (EU-MS) and other Mediterranean countries. A juxtaposition of overlapping governance instruments occurred recently in the region, with the implementation of both the Marine Strategy Framework Directive (MSFD) for EU-MS and the Ecosystem Approach Strategy (ECAP) for all Mediterranean countries, including EU-MS. Both MSFD and ECAP are structured around vision-driven processes to achieve Good Environmental Status and a Healthy Environment, respectively. These processes have clear ecosystem-based, integrated policy objectives to guarantee the preservation and integrity of Mediterranean marine ecosystem goods and services. However, adoption of these instruments, especially those related to the new EUMS directives on marine policy, could result in a governance gap in addition to the well-known economic gap between the EU and the non-EU political blocs. We identify two complementary requirements for effective implementation of both MSFD and ECAP that could work together to reduce this gap, to ensure a better alignment between MSFD and ECAP and better planning for stakeholder engagement. These are key issues for the future success of these instruments in a Mediterranean region where discrepancies between societal and ecological objectives may pose a challenge to these processes.
\end{abstract}

Key Words: ecosystem approach; environmental status; governance; legislation implementation; marine environment; Mediterranean; shared vision

\section{INTRODUCTION}

The Mediterranean region is home to some of the world's oldest cultures and has been exploited and managed by humans for more than 8000 years (Trump 1980). This long history of development in the region has resulted in environmental degradation that accelerated during the last decades of the 20th century (EEA 2008, Cinnirella et al. 2013). Mediterranean countries participate in many different initiatives for environmental protection in attempts to halt this degradation (Suárez de Vivero 2012, Suárez de Vivero and Rodríguez Mateos 2015), but differences in legal requirements between countries could potentially limit conservation and management efforts. Despite the complex geopolitical setting of the region, two recent initiatives have been launched to maintain marine ecosystem integrity while enabling sustainable use of ecosystem goods and services. We provide a critical review of the similarities and differences between these two initiatives: the Marine Strategy Framework Directive (MSFD 2008/56/EC; EC 2008) for European Union Member States (EUMS) and the Ecosystem Approach Strategy (ECAP) for all the Mediterranean countries under the United Nations Environmental Program (UNEP) Mediterranean Action Plan (MAP; UNEPMAP 2008). Shared governance has the potential to produce a synergistic approach toward fostering both strategy implementation and objective targeting. It is necessary to focus on a shared vision between the MSFD and MAP approaches combined with complete engagement of stakeholders to facilitate progress toward effective implementation of both MFSD and ECAP (see the proposed timeline in Fig. 1).

\section{GEOPOLITICAL CONTEXT AND GOVERNANCE INSTRUMENTS}

The Mediterranean Sea is surrounded at present by 22 coastal states, excluding UK sovereignty, that claim national jurisdiction over parts of the sea. This complexity is also reflected in the jurisdictional structure of its maritime space, with the degree of responsibility for EU countries under MFSD depending on the geographical characteristics of each state (Fig. 2a, b). Changes are occurring at a marine jurisdictional level. For example, in 2012 France approved an Exclusive Economic Zone; Italy approved an Ecological Protection Zone; Slovenia currently claims an Ecological Protection Zone; and Croatia claims an Ecological and Fisheries Protection Zone incorporating specific features of an Exclusive Economic Zone, mainly related to the protection of the marine environment. The dispute over water sovereignty among countries (Suárez de Vivero 2012) may also affect the achievement of environmental objectives. The degree of internationalization of the Mediterranean Sea's waters is also relevant: $29.2 \%$ of the waters are high seas (Fig. 2c), which theoretically limits intervention in environmental affairs by coastal states because political and security issues are governed by international norms. Nonetheless, the entire sea floor does fall within the control of national jurisdictions.

A diverse range of international maritime governance instruments (Table 1) involve the majority of Mediterranean Sea states. In addition, actions taken by individual states and other regional bodies pertain to Mediterranean Sea management. The different and overlapping initiatives for environmental protection

${ }^{1}$ CNR-Institute of Atmospheric Pollution Research, ${ }^{2}$ CSIC-Centre d'Estudis Avançats de Blanes, ${ }^{3}$ University of Seville, ${ }^{4}$ The Scottish Association for Marine Science, ${ }^{5}$ University of Padova, ${ }^{6}$ University of Algarve, ${ }^{7}$ Centre for Environment, Fisheries and Aquaculture Science, ${ }^{8}$ Sistema d'observació i predicció costaner de les Illes Balears, ${ }^{9}$ CSIC-Centre d'Investigació i Desenvolupament, ${ }^{10}$ University of East Anglia, ${ }^{11}$ University of Western Brittany, ${ }^{12}$ University of Plymouth 
Fig. 1. Synthetic comparison of Marine Strategy Framework Directive (MSFD) and Ecosystem Approach Strategy (ECAP) milestones (UNEP-MAP 2012; modified from O'Higgins and Roth 2010)

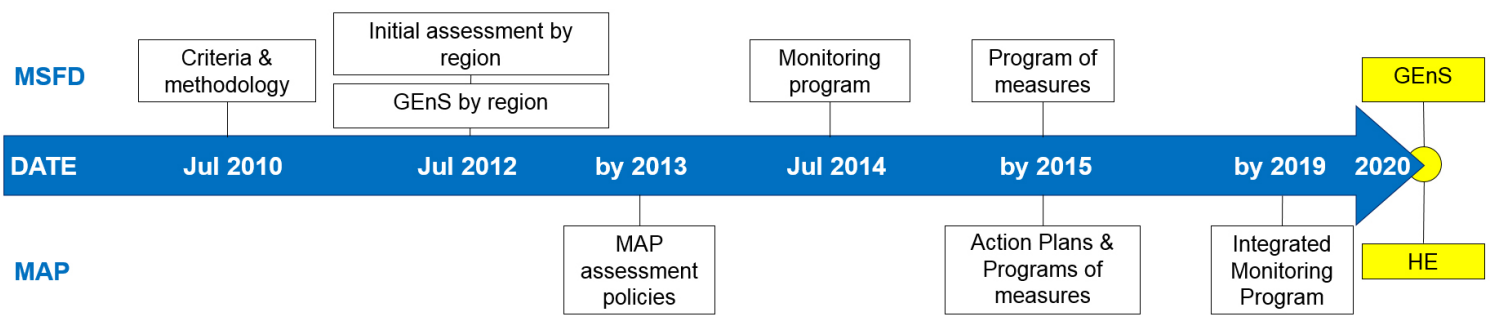

(Suárez de Vivero 2012, Suárez de Vivero and Rodríguez Mateos 2015) range from international conventions, e.g., United Nations Convention on the Law of the Sea, Ramsar, the Convention on Biological Diversity, and the Basel Convention on the Control of Transboundary Movements of Hazardous Wastes and their Disposal, to regional initiatives such as UNEP-MAP and $\mathrm{H} 2020$. Some are specific to the coastal and marine environment. The EU-MS have adopted binding legislation to protect the environment (EC 1992, 2000, 2001, European Parliament 2002, EC 2008, 2009a, 2014a).

Table 1. Legal-institutional marine governance forms in the Mediterranean that involve both EU and non-EU countries (Suárez de Vivero and Rodríguez Mateo 2015).

\begin{tabular}{ll}
\hline International & - United Nations Convention on the Law of the Sea \\
initiatives & - Conservation agreements \\
& - Fishing treaties \\
& - Agreements on dumping of waste and pollutants \\
& - UNEP-Regional Seas Programme \\
Regional & - Mediterranean Action Plan: Barcelona Convention and \\
initiatives & protocols; Blue Plan; MEDPOL Programme \\
& - General Fisheries Council for the Mediterranean \\
& - EU initiatives \\
& - Other initiatives: METAP (World Bank); NGOs \\
& (IUCN); subregional initiatives (Declaration on the \\
& Conservation and Sustainable Development of the \\
& Alboran Sea, Pelagos Sanctuary, RAMOGE Agreement, \\
& etc.) \\
& - Transposition of international law \\
National & - General environmental legislation (natural spaces, \\
initiatives & pollution prevention, coastal protection, and coastal and \\
& marine environment protection, etc.) \\
& - Legislation on marine aspects (fishing, protected marine \\
& areas, navigation, exploitation of nonliving resources, \\
etc.)
\end{tabular}

During the last decade, both the European Commission (EC) through MFSD and UNEP through MAP (UNEP-MAP 2008) have made commitments to foster the sustainable use of marine resources with the stated vision of achieving and/or maintaining a clean, healthy, and productive sea. However, the overlap in the jurisdictional competence and vision of these two initiatives has yet to be resolved. Governance complexity creates institutional ambiguity for implementing MFSD at the Mediterranean level because the EU has jurisdiction only over $36 \%$ of the Mediterranean (Fig. 2a), which with the future accession of candidate countries such as Montenegro, Turkey, or Albania may increase to $46 \%$. UNEP-MAP includes political institutions from all the countries of the Mediterranean Basin (van Leeuwen et al. 2012).

\section{The Marine Strategy Framework Directive}

The MSFD establishes a framework within which each EU-MS must take the necessary steps to achieve or maintain Good Environmental Status (GEnS) of the marine environment by 2020. The MSFD has developed a vision-driven process that uses the Ecosystem Approach (EA) to achieve GEnS within a particular marine region or subregion. The MSFD imposes a legal obligation on those EU-MS countries with jurisdiction over Mediterranean maritime waters, including the continental shelf. Each individual EU-MS is responsible for its waters and for reaching predefined targets that must be documented according to a well-defined time line. Wider assessment/reporting scales are desirable, but are not mandatory. Failure to comply with MFSD requirements may lead to legal action against an EU-MS. The EC therefore has specific legal tools to control the implementation of MFSD. Although each EU-MS is responsible for implementing MFSD, the need to collaborate with other EU-MS or non-EU countries in the same region or subregion is also mentioned in the directive. However, although MFSD involves international obligations and commitments (EC 2008, 2013a), administrative compliance with the directive is uneven: all EU-MS have transposed the directive (article 26), completed the initial assessment (article 8), determined GEnS (article 9), and defined environmental targets and indicators (article 10). However, there is only limited coherence at regional and subregional levels (Palialexis et al. 2013, Dupont et al. 2014).

Although conformity and compliance with MFSD across member states are important, a more fundamental question is whether MSFD implementation can resolve marine and coastal environmental problems in the Mediterranean. A very simple indicator of how Mediterranean EU-MS do not focus their policies on the environment is the number of infringements related to the environment opened by the EU Directorate-General for the Environment (Fig. 3). Nonetheless, there are collaborative efforts relevant to the implementation of MFSD. For example, the new multiannual recovery plan for Eastern blue fin tuna (Thunnus thynnus) adopted by the International Commission for the Conservation of Atlantic Tunas (EC 2013b) represents a success for Mediterranean regional cooperation. 
Fig. 2. Map and bar charts of Mediterranean EU and non-EU countries (ISO 3166-2 Codes) jurisdictions (modified from Suárez de Vivero 2012). Further detailed maps can be found in Suárez de Vivero's 2012 publication.

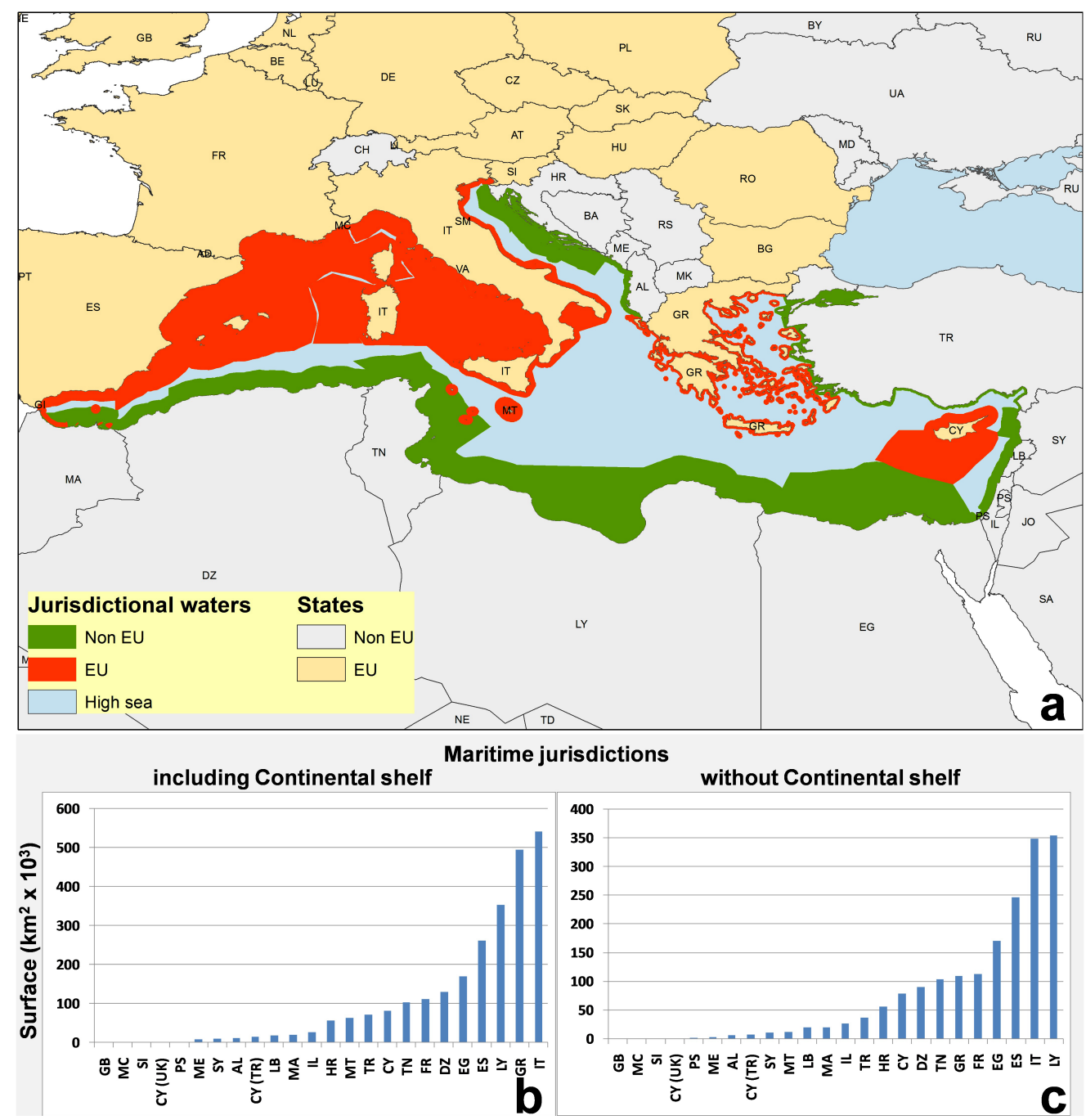

Fig. 3. Statistics on environmental infringements in European Countries (ISO 3166-2 Codes) for the years 2010, 2011, and 2012 (EC 2013c).

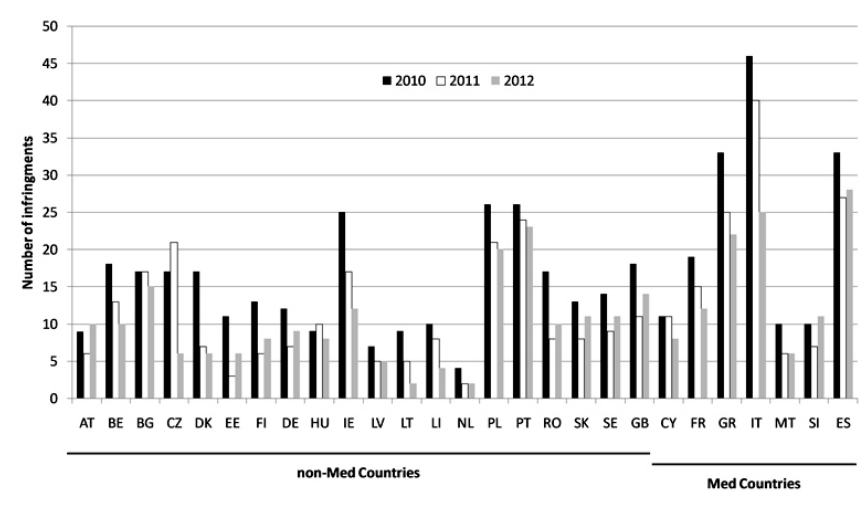

The Mediterranean Ecosystem Approach Strategy

The Barcelona Convention covers all the maritime waters in the Mediterranean Basin, from the open sea to sheltered coves. In 1975, 16 Mediterranean countries and the European Community adopted MAP, of which phase II, the 1995 revision, entered into force in 2004. The Mediterranean Ecosystem Approach Strategy (ECAP) was proposed in 2005 and was aimed, among other objectives, at strengthening efforts to decontaminate the Mediterranean Sea to achieve a Healthy Environment status by 2020. The ECAP was eventually launched under the MAP Five Year Programme (2010-2014), within the Barcelona Convention (UNEP-MAP 2009). The MAP is legally binding because it has been adopted by the contracting parties to advance the implementation of the convention and its protocols, as well to take into account relevant new global and regional developments. Seven protocols were written (Table 2) to create the international legal framework for the Mediterranean region. These protocols 
have now been incorporated into ECAP, which is essentially organized around four themes, reflecting the main deliverables expected from the contracting parties: (1) adoption of regional targets and the establishment of a definition for Healthy Environment; (2) development of a regional integrated monitoring program based on indicators and targets; (3) coupling of integrated assessment with socioeconomic analysis for the Mediterranean ecosystem; and (4) establishment of an assessment cycle through the development of a UNEP-MAP policy on the assessment of marine and coastal environments.

Table 2. Seven protocols addressing specific aspects of Mediterranean environmental conservation (UNEP-MAP 2013).

\begin{tabular}{|c|c|c|c|}
\hline Protocol & Adopted & Amended & $\begin{array}{c}\text { Entered } \\
\text { into force } \\
\end{array}$ \\
\hline $\begin{array}{l}\text { Prevention and elimination of pollution } \\
\text { of the Mediterranean Sea from ships and } \\
\text { aircraft or incineration at sea (Dumping } \\
\text { Protocol) }\end{array}$ & 1976 & 1995 & $\begin{array}{l}\text { Not yet } \\
\text { in force }\end{array}$ \\
\hline $\begin{array}{l}\text { Protection of the Mediterranean Sea } \\
\text { against pollution from land-based } \\
\text { sources and activities (LBS Protocol) }\end{array}$ & 1980 & 1996 & 2008 \\
\hline $\begin{array}{l}\text { Protection of the Mediterranean Sea } \\
\text { against pollution resulting from the } \\
\text { exploration and exploitation of the } \\
\text { continental shelf and the seabed and its } \\
\text { subsoil (Offshore Protocol) }\end{array}$ & 1994 & & 2011 \\
\hline $\begin{array}{l}\text { Specially protected areas and biological } \\
\text { diversity in the Mediterranean (SPA \& } \\
\text { Biodiversity Protocol) }\end{array}$ & 1995 & & 1999 \\
\hline $\begin{array}{l}\text { Prevention of pollution of the } \\
\text { Mediterranean Sea by transboundary } \\
\text { movements of hazardous wastes and } \\
\text { their disposal (Hazardous Wastes } \\
\text { Protocol) }\end{array}$ & 1996 & & 2008 \\
\hline $\begin{array}{l}\text { Cooperation in preventing pollution } \\
\text { from ships and, in case of emergency, } \\
\text { combating pollution of the } \\
\text { Mediterranean Sea (Prevention and } \\
\text { Emergency Protocol) }\end{array}$ & 2002 & & 2004 \\
\hline $\begin{array}{l}\text { Integrated Coastal Zone Management in } \\
\text { the Mediterranean (ICZM Protocol) }\end{array}$ & 2008 & & 2011 \\
\hline
\end{tabular}

Under ECAP, all Mediterranean states need to apply Healthy Environment targets at a regional or subregional level for their jurisdictional waters. Ideally, each signatory country should implement an integrated monitoring program; adopt new regional management plans, e.g., for Special Protected Areas (EC 1992, EC 2009a) and Special Protected Areas of Mediterranean Importance; and update and implement their National Action Plans to control land-based pollution and protect biodiversity, thus reflecting ECAP's environmental targets and commitments (UNEP-MAP 1995). ECAP unifies the many sectoral analyses and management measures of MAP into a single integrated framework (UNEP-MAP 2012). A MAP Compliance Committee reviews the progress of the implementation by the signatories to the Barcelona Convention and its protocols. A periodical review of progress focuses on specific environmental targets every four to five years after the initial setting of those targets. However, because this application requires close collaboration between countries within each specific regional or subregional level, the responsibilities of individual states cannot be easily assessed when objectives are not achieved. Indeed the implementation has not been clearly defined legally; therefore, most of the actions have been only partially implemented at best, or not at all, requiring the external support of the Global Environmental Facility to accelerate implementation. This is in part because of limited funding, but also because of a lack of political priority, a lack of inclusive environmental governance, and the limited public awareness of the issues at stake (EU 2006). The Mediterranean European Neighbourhood countries (e.g. Algeria, Egypt, Israel, Jordan, Lebanon, Morocco, Palestinian Authority, Syria, and Tunisia) have even greater difficulties than the EU-MS with the implementation and compliance with ECAP because of limited human resources, and in some instances limited technical or economic capacity with which to achieve the Healthy Environment objective (EC 2009b).

\section{EMPHASIZING VISION ALIGNMENT BETWEEN MSFD AND ECAP}

\section{Effective implementation}

Effective implementation of MFSD and ECAP in the Mediterranean requires a synergy between EU-MSFD and MAPECAP strategies (UNEP-MAP 2010). A definition of the required strategic goals to achieve GEnS and Healthy Environment should be developed at the highest political level. The MSFD has defined EA as the framework to be used for the management of the marine environment (Agardy and Adler 2005, Farmer et al. 2012). Similarly, parties adhering to MAP have also agreed to use EA to manage human activities with a view to conserving natural marine heritage and protecting vital ecosystem services (UNEPMAP 2012). Thus, EA could provide a framework to reach consensus between MFSD and ECAP in contexts in which this seems difficult to achieve. Following the EA framework, the Descriptors and Indicators of MSFD and Ecological Objectives of ECAP (Table 3) are similar.

To steer these processes, the focus of management needs to shift from "humanity outside the ecosystem" to the "human-innature" concept, from managing commodities to sustaining the production potential of ecosystem goods and services (Cheong 2008, Forst 2009). Regional assessments in the Mediterranean confirm that the capacity of the sea to continue providing natural resources and ecosystem services is declining as a result of human activities (Coll et al. 2010, 2012, Sala et al. 2013). Understanding the economic benefits of a healthy environment is useful in choosing priority actions to avoid further environmental degradation. The benefits provided by the Mediterranean Sea to the surrounding countries are considerable, yet an in-depth understanding of how ecosystem services underpin economic and social well-being within the region is limited. Nevertheless, a comparison between the value of the benefits provided by the Mediterranean and the value provided by all European seas for prominent categories of economic sectors and human activities is presented in Table 4. Although individual values are not theoretically homogeneous, and for this reason should not be added together, the value of the benefits provided by the Mediterranean Sea currently accounts for $36.6 \%$ of the total value provided by European seas, using high-end estimates. Unsurprisingly, the Mediterranean Sea delivers considerable recreational benefits, measured by the high visitor expenditure and willingness to pay for good bathing water quality. In addition, 
Table 3. Comparison between EU-Marine Strategy Framework Directive (MSFD) and Mediterranean Action Plan-Ecosystem Approach Strategy (MAP-ECAP) vision, strategic goals, and ecological objectives already defined. With the exception of MAP-ECAP Objective 8 they are almost identical

\begin{tabular}{lr}
\hline EU-MSFD & MAP-ECAP \\
\hline Good Environmental Status (GEnS) & $\begin{array}{r}\text { VISION } \\
\text { A healthy Mediterranean with marine and coastal ecosystems that are } \\
\text { productive and biologically diverse for the benefit of present and future } \\
\text { generations }\end{array}$ \\
STRATEGIC GOALS
\end{tabular}

(i) to protect more effectively the marine environment across Europe;

(i) to protect, allow recovery and, where practicable, restore the structure and function of marine and coastal ecosystems thus also protecting biodiversity, to achieve and maintain good ecological status and allow for their sustainable use;

(ii) to achieve Good Environmental Status of the EU's marine waters by (ii) to reduce pollution in the marine and coastal environment so as to 2020 and to protect the resource base upon which marine-related economic and social activities depend; minimize impacts on and risks to human and/or ecosystem health and/ or uses of the sea and the coasts;

(iii) to constitute the vital environmental component of the Union's future (iii) to prevent, reduce, and manage the vulnerability of the sea and the maritime policy, designed to achieve the full economic potential of oceans coasts to risk induced by human activities and natural events (UNEPand seas in harmony with the marine environment.

DESCRIPTOR / OBJECTIVES

1. Biological diversity is maintained. The quality and occurrence of habitats and the distribution conditions

2. Nonindigenous species introduced by human activities are at levels that do not adversely alter the ecosystems

3. Populations of all commercially exploited fish and shellfish are within safe biological limits, exhibiting a population age and size distribution that is indicative of a healthy stock.

4. All elements of the marine food webs, to the extent that they are known, occur at normal abundance and diversity and levels capable of ensuring the long-term abundance of the species and the retention of their full reproductive capacity.

5. Human-induced eutrophication is minimized, especially adverse effects thereof, such as losses in biodiversity, ecosystem degradation, harmful algae blooms, and oxygen deficiency in bottom waters.

6. Sea-floor integrity is at a level that ensures that the structure and functions of the ecosystems are safeguarded and benthic ecosystems, in particular, are not adversely affected.

7. Permanent alteration of hydrographical conditions does not adversely affect marine ecosystems.

8. Concentrations of contaminants are at levels not giving rise to pollution effects.

9. Contaminants in fish and other seafood for human consumption levels established by community legislation or other relevant standards.

10. Properties and quantities of marine litter do not cause harm to the coastal and marine environment.

11. Introduction of energy, including underwater noise, is at levels that do not adversely affect the marine environment.
MAP 2008)

\section{ECOLOGICAL OBJECTIVES}

1. Biological diversity is maintained or enhanced. The quality and occurrence of coastal and marine habitats and the distribution and abundance of coastal and marine species are in line with prevailing physiographic, hydrographic, geographic, and climatic conditions.

2. Nonindigenous species introduced by human activities are at levels that do not adversely alter the ecosystem.

3. Populations of selected commercially exploited fish and shellfish are within biologically safe limits, exhibiting a population age and size distribution that is indicative of a healthy stock.

4. Alterations to components of marine food webs caused by resource extraction or human-induced environmental changes do not have longterm adverse effects on food web dynamics and related viability.

5. Human-induced eutrophication is prevented, especially adverse effects thereof, such as losses in biodiversity, ecosystem degradation, harmful algal blooms, and oxygen deficiency in bottom waters. 6. Sea-floor integrity is maintained, especially in priority benthic habitats.

7. Alteration of hydrographic conditions does not adversely affect coastal and marine ecosystems.

8 . The natural dynamics of coastal areas are maintained and coastal ecosystems and landscapes are preserved.

9. Contaminants cause no significant impact on coastal and marine ecosystems and human health.

10. Marine and coastal litter does not adversely affect coastal and marine environments.

11. Noise from human activities causes no significant impact on marine and coastal ecosystems. results show that Southern European countries are willing to pay more to reduce the risk of illness because of poor water quality compared with other European countries.

An example of how the ecosystem services provided by the Mediterranean accrue to the whole of Europe and beyond is the conservation of seagrasses" "blue carbon." The value of carbon storage in the endemic seagrass Posidonia oceanica was found to be more than three times higher than that estimated for all European coastal salt marshes (Luisetti et al. 2013), providing a strong rationale for the protection of this unique Mediterranean habitat (UNEP-MAP 2010). Therefore, protection of seagrasses can lead to strong carbon-storage control.
Effective implementation of MFSD and ECAP would be particularly beneficial if managers could follow a standardized stepwise process to ensure consistency in the development of management measures to address legislative and regulatory requirements. Several systems, such as the Ecosystem-Based Management System (Sardá et al. 2011), have been designed recently with the objective of providing a standard methodology to assist managers of coastal and marine environments in the practical use of EA by introducing a common set of tools and procedures, and a common language to facilitate knowledge transfer and capacity building. The use of standards for practitioners could foster the implementation of the human-innature concept, accelerating the acceptance of EA. 
Table 4. Mediterranean share of current welfare benefits provided by European Seas (base year 2010; Data source: Cooper et al. 2011). The table shows that the value of the Mediterranean Sea space for freight transport is high

\begin{tabular}{|c|c|c|c|}
\hline \multirow[t]{2}{*}{ Sector/Activity } & $\begin{array}{l}\text { Mediterranean } \\
\text { (A) }\end{array}$ & $\begin{array}{c}\text { European Seas } \\
\text { (B) }\end{array}$ & $\mathrm{A} / \mathrm{B}$ \\
\hline & Million $€$ per annuum & Million $€$ per annuum & $\%$ \\
\hline \multicolumn{4}{|l|}{ Fisheries } \\
\hline - capture & 2262 & 8,675 & 26.1 \\
\hline - mariculture ${ }^{\dagger}$ & 605 & 5,515 & 11.0 \\
\hline Freighttransport & $6345-28,784$ & $13,746-62,360$ & 46.2 \\
\hline Recreation (visits) ${ }^{\ddagger}$ & 15,205 & 31,394 & 48.4 \\
\hline \multicolumn{4}{|c|}{ Recreation (water quality) } \\
\hline - health risk & 7723 & 15,327 & 50.4 \\
\hline - eutrophication & 4656 & 40,342 & 11.5 \\
\hline \multicolumn{4}{|l|}{ Carbon storage } \\
\hline - salt marshes & $0.2-120$ & $0.6-298$ & $33.3-40.3$ \\
\hline - seagrass & $31-1,095$ & $31-1,095$ & 100 \\
\hline Total & $36,827-60,452$ & $115,031-165,007$ & \\
\hline Low end & & & $32.0-22.3$ \\
\hline High end & & & $52.6-36.6$ \\
\hline
\end{tabular}

\section{From policy fragmentation to policy alignment}

The MSFD and ECAP clearly share a common approach in recognizing multiple categories of environmental degradation within the marine environment. However, although both stem from a recognition of interacting multisectoral drivers, in practice there are many examples of a fragmented approach to marine management within the Mediterranean and in other European regional seas (Potts et al. 2012, O'Higgins et al. 2014a). As a consequence, policy objectives at various levels of government may not necessarily be coherent enough to ensure the integrity of the marine ecosystem (EU 2014). The MSFD and ECAP have clear time lines for implementation (Fig. 1) and have similar objectives, i.e., GEnS and Healthy Environment, which are independent of national jurisdictional waters. Both aim to establish a Programme of Measures by 2015 to achieve their respective goals by 2020 . Although MAP does not directly assist EU-MS with implementation of MFSD, the subregional initial assessment prepared by MAP under the EA framework is directly relevant to Mediterranean EU-MS in their Initial Assessment required under MFSD. Even if MFSD is not applicable to the whole of the Mediterranean, its philosophy and principles could nonetheless be applied to the whole marine Mediterranean domain through the development of a shared vision via MAP.

Both MFSD and ECAP are committed to seeking mutual collaboration for the protection of the Mediterranean marine environment. However, there are important differences in the capacity for implementing specific measures or initiatives, with the implementation of such goals driven by different visions and concerns between different jurisdictions (Bainbridge et al. 2011, Angelidis 2012). The alignment of MFSD and ECAP would focus the attention of all Mediterranean countries on the two fundamental concepts: a vision-driven process and a single integrated framework.
There are a number of obstacles to policy alignment that significantly affect the implementation of MSFD and ECAP, thereby hindering the achievement of GEnS and Healthy Environment for the Mediterranean Sea. These obstacles should be removed as soon as possible.

\section{Economic aspects}

Several of the Mediterranean coastal states have been hit particularly hard by the global crisis, whereby economic restrictions have made it difficult to implement the necessary programs of measures to achieve GEnS. Furthermore, economic disparity, jurisdictional conflicts, and rapid political changes have contributed to the lack of a shared action toward achieving environmental goals within the region, including the implementation of MFSD (O'Higgins et al. 2014a). Harmonization of monitoring of MFSD indicators around Europe is also an issue; a recent expert survey highlighted the concern that, although all EU-MS will comply with the requests of MFSD as expected, the data gathered will be heterogeneous and difficult to compare between the member states (HELCOM 2012). Limited communication between scientists within and between EU-MS has reduced both interdisciplinary cooperation and the transfer of relevant scientific information to policy makers.

Although properties of ecosystem integrity are reflected in the GEnS descriptors, establishing connections between ecosystem change and benefits to human welfare should lead to indicators of greater societal relevance (O'Higgins et al. 2014b) and more proactive approaches to conservation, which may also facilitate MSFD implementation (Sardá 2013). The ecosystem service concept (Ehrlich and Ehrlich 1981, Fisher et al. 2009) integrates the connections between humans and the environment, which is the ultimate goal of the new Integrated Maritime Policy. However, different ecosystems provide a complex combination of different 
services; thus, problems may arise when an economic valuation of ecosystem services is required, mainly because of the complexity of the ecosystems and the interdependency of the services provided. In summary, an environmental program of measures can have economic justification because societal benefits may be enhanced when environmental quality is improved and the full welfare benefits from ecosystem services are quantified accurately (Goulding et al. 2014). However, disentangling the joint production of ecosystem services as well as the linked nature of GEnS descriptors remains a challenge (O'Higgins et al. 2014b). The decline in certain drivers that can accompany economic recession should also be seen as an opportunity to direct efforts toward environmental objectives ( Potts et al. 2015).

\section{Policy aspects}

Sometimes, aspects of policy can be obstacles to a coherent implementation of legal instruments. Different European policies dealing with conservation and the use of the sea are not always perfectly coherent. Indeed, the approaches for implementing the legal instruments, including the Habitat Directive, Natura 2000, the Water Framework Directive, the Integrated Maritime Policy, and the Common Fisheries Policy, are still far from being truly integrated among the EU-MS (van Hoof and van Tatenhove 2009, Borja et al. 2010, Ounanian et al. 2012, van Leewen et al. 2012). As recognized by the EC (2014b), "these pieces of legislation, although crucial complementary tools to the protection of marine waters, contribute to the protection of the sea only from specific pressures resulting in a fragmented and sectoral approach."

The need for achieving common targets within common time frames for the implementation of MFSD contrasts with Water Framework Directive 2000/60/EC (WFD; EC 2000), another major piece of legislation that aims at improving water quality within Europe, including coastal waters. Under the concept of subsidiarity, each EU-MS has produced an individual scheme for the implementation of WFD, while the EC provides a common framework applying to all EU-MS for the implementation of MFSD (Borja et al. 2010). Environmental policies in general, and marine policies in particular, have different priorities in different EU countries and mostly operate at different time scales. See, for example, the top environmental issues discussed by the EU institutions under the Greek presidency from January through June 2014: climate and energy, emissions from international aviation, shale gas, waste and resource efficiency, and alternative fuel strategy.

An example showing how the implementation of other policies conflict with MFSD is the application of WFD. The WFD is intended to improve water quality in river catchments (Borja et al. 2010). A specific example is the Adriatic Sea, which supports one of the largest fisheries in the Mediterranean. The ItalianCroatian fishery targeting small pelagic fish, i.e., anchovies (Engraulis encrasicolus) and sardines (Sardina pilchardus), accounts for approximately $70 \%$ of total Adriatic catches (Mulazzani et al. 2012) and is of great economic importance. Here, intense planktonic production underpins the productivity of the fish and invertebrates necessary to sustain a fishery; this biological production is mainly supported by nutrient inputs originating from the Po river catchment that drains into the
Northern Adriatic (Barausse et al. 2009, 2011). Sectoral policies, e.g., the Common Agricultural Policy, and the adoption of WFD have committed watershed managers to reduce nutrient loads from EU riverine systems, but this goal could endanger the productivity of small pelagic fish stocks. Achieving GEnS requires healthy commercial fish stocks, for which fishing mortality should be equal to or lower than the level for maintaining harvest at the Maximum Sustainable Yield (EC 2010). But Maximum Sustainable Yield in this case also depends on the productivity of the marine ecosystem, which can be dramatically altered by the nutrient load of human origin discharged by rivers (Fig. 4; Barausse et al. 2011). To prevent resource collapse in the Adriatic, the fishing effort targeting anchovies and sardines should be managed so that $<40 \%$ of stock depletion is caused by fishing (Santojanni et al. 2006). However, if ecosystem productivity is further decreased by reducing nutrient inputs, the healthy fish stocks required by MFSD may be difficult to obtain without even greater, socially undesirable reductions in fishing effort. In short, one aim of WFD is to reduce nutrient discharges to water bodies, e.g., to prevent eutrophication, which could decrease the productivity of coastal seas to levels that would make the current fishing pressure potentially unsustainable, thus jeopardizing MFSD goals. To achieve GEnS in the Mediterranean, the target requirements of these overlapping policies need to be aligned.

Fig. 4. Relative abundance (CPUE, Catch Per Unit Effort) of sardine (Sardina pilchardus) in the Northern Adriatic Sea (Barausse et al. 2011; data refer to Chioggia, a city hosting a major fishery of the Northern Adriatic Sea), and phosphate inputs entering the ecosystem through the Po river (UNEPMAP-MEDPOL 2003, Cozzi and Giani 2011). Nutrient inputs peaked from the mid-1970s to the mid-1980s causing severe eutrophication, but were subsequently halved because of a phosphate ban in household detergents and treatment of waste waters, thus reducing system productivity (Artioli et al. 2008, Mozetič et al. 2010). These changes in nutrient inputs strongly influenced the biomass of Adriatic fishing resources (Barausse et al. 2011): in the figure, sardine abundance closely mirrors the trajectory of nutrient inputs over time.

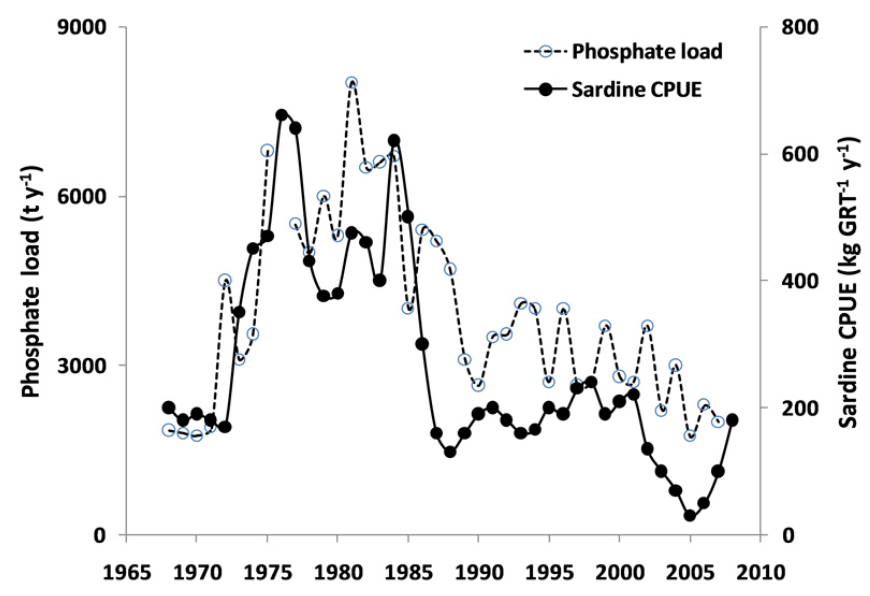

Management aspects

Integrated approaches and policy objectives such as those introduced by MFSD can only be effective if adequate management measures are carried out in combination with 
effective governance structures. This was the basis for the adoption of the Integrated Coastal Zone Management (ICZM) protocol for the Mediterranean Sea, which is an ecosystem-based instrument that links catchments with coastal zones. The proposed directive, establishing a framework for maritime spatial planning and integrated coastal management, may also help to coordinate the application of the different policies relating to the coastal zone and coastal zone activities through EA (EC 2014b).

The concept of GEnS in MFSD gives integrated management a clear objective at which to aim (Cormier et al. 2013). Although currently fragmented policies and administrative jurisdictions are an obstacle to the sustainable use of the Mediterranean Sea, there is the potential for change through the clear procedures required for MSFD implementation aligned with other integrated tools such as the Strategic Environmental Assessment combined with Marine Spatial Planning. To facilitate this type of management, new tools that combine adaptive, proactive, and transparent principles are recommended (Sardá et al. 2011), as well as building interoperable systems for the exchange of information (Cinnirella et al. 2012).

\section{ENGAGING WITH MULTIPLE STAKEHOLDERS}

The EA could help to ensure a healthy Mediterranean marine and coastal environment, prosperous coastal communities, and viable coastal industries; but achievement of these goals requires that all the relevant societal sectors are involved in its application (Haley 2011, PISCES 2014). A multiple-stakeholder platform is of indisputable benefit, as was recently demonstrated in the PEGASO Project (Breton and Skaricic 2013). Such a platform should allow stakeholders adequate and timely participation in transparent decision-making processes, provide them with tools such as full-cost accounting methods to calculate damage and restoration costs, and provide the minimum levels of natural capital needed for sustainability (Haines-Young and Potschin 2011, Maccarrone et al. 2014).

The MSFD and ECAP processes remain fragmented because their implementation is restricted to national efforts and involves limited collaboration with nonofficial stakeholders. The effective implementation of MFSD and ECAP in the Mediterranean Sea requires a move from governance approaches developed to address specific competencies and concrete tasks to other much more flexible approaches that account for the multiple uses of the sea. This requires establishing a permanent interaction between related stakeholders (Tallis et al. 2010).

The identification of stakeholders in places where MSFD-ECAP is implemented would allow the selection of participants with the capacity to prioritize the actions and issues necessary to produce an effective management plan for implementation. Facilitating the dialogue between all relevant stakeholders to develop and share a common vision for the integrity of the Mediterranean, i. e., GEnS-Healthy Environment using the EA, would help create a common understanding of the future actions necessary to bring both MFSD and ECAP into effective compliance, regardless of possible political constraints. If national agencies consider EA frameworks as just another piece of administrative compliance, it is unlikely that any transformation of present managerial practices related to the marine environment will occur. A shared vision among the main actors/stakeholders could transform the implementation of MFSD and ECAP from merely administrative compliance to effective compliance. If this process could be carried out using a standardized procedure, it would be of major benefit to all stakeholders.

\section{CONCLUSIONS}

Humans have long inhabited the shores of the Mediterranean Sea, thereby producing significant anthropogenic-driven change that has accelerated over the last decades. The large benefits provided by Mediterranean Sea ecosystems, estimated by Cooper et al. (2011) to be $36.6 \%$ of the total current welfare benefits provided by European seas, have been recognized to be under threat because anthropogenic pressures have degraded their status (Coll et al. 2010, 2012, Cinnirella et al. 2013). Although MAP was created in 1975 to address the environmental degradation of the Mediterranean, there has been limited funding, low political priority, a lack of environmental management initiatives, and limited public awareness, all of which has been made worse by the substantial socioeconomic gap between the EU political bloc and the non-EU political bloc (EU 2006). In addition to the socioeconomic gap, there is now an expanding governance gap with new EU initiatives including an expansion of the Integrated Maritime Policy and its instruments, such as the recently approved Directive on Maritime Spatial Planning (EU 2014), which strengthens and deepens the concept of EA.

Currently two juxtaposed strategies, MFSD and ECAP, overlap in the Mediterranean Sea. Although differences exist between both instruments, these should not constitute a serious obstacle to possible harmonization of the two processes. Both MFSD and ECAP are committed to applying the EA framework, particularly when it is difficult to find agreement within a specific sociopolitical context. To advance the application of EA with the goal of achieving GEnS in the Mediterranean Sea, we have identified two complementary requirements for its implementation: (1) vision alignment between MSFD and ECAP must be emphasized, with a better road map to reach common strategic goals and adequate management plans; and (2) there must be a coherent plan to engage stakeholders, to facilitate the understanding of what a healthy environment actually is, and to introduce the necessary measures and actions.

\section{Vision alignment}

Both MSFD and ECAP require dialogue, common directions, and, ideally, a shared vision to remove obstacles and establish a systems perspective. Effective implementation should drive the focus of management into a general human-in-nature concept, not just the management of necessary commodities, but also sustainable production of ecosystem goods and services. Use of standard methodologies for management, such as the EcosystemBased Management System framework (Sardá et al. 2011), could introduce a common set of tools and procedures, and a common language that would facilitate knowledge transfer and capacity building in a harmonized fashion. A major effort to establish coordinating mechanisms, e.g., high-level policy planning bodies, should deal with the issue of policy fragmentation. Governance mechanisms need to operate both at the level of setting strategic objectives across jurisdictions and at the level of operational management to link management measures to the strategic objectives. 


\section{Stakeholder engagement}

The common approach adopted today of engaging stakeholders and specific competencies only when necessary to solve concrete tasks should be replaced by a much more flexible and integrated concept with permanent interaction with the stakeholders. The institutional fragmentation of policies and objectives could encourage the impression that environmental strategies are just targets of administrative compliance. A clear engagement with stakeholders with the final objective of sharing a common desired vision should bring both MFSD and ECAP to effective compliance, rather than encouraging strategies aimed simply at ensuring compliance with legislation.

The future of the Mediterranean Sea is not to balance development against conservation, but rather to emphasize that conservation can facilitate further sustainable development. There is a large consensus that application of the EA philosophy and principles is necessary to attain a clean, healthy, and productive Mediterranean Sea. Nevertheless, there still are many obstacles to adequate implementation. These include the absence of political and public perception of the priorities concerning the quality of the marine domain, as well as the complexity and potentially conflicting jurisdictional policy objectives of various levels and agencies within the governments in a given geographical area. However, there are no fundamental reasons why these obstacles should continue to be an impediment to achieving GEnS for the Mediterranean Sea.

Responses to this article can be read online at: http://www.ecologyandsociety.org/issues/responses. $\mathrm{php} / 7065$

\begin{abstract}
Acknowledgments:
We acknowledge the KnowSeas project (grant number 226675) for supporting this work, the Know Seas internal reviewers for improving the paper, and those anonymous referees for their meaningful comments. Special thanks to Michael Angelids for his invaluable comments on the earliest draft manuscript concerning the United Nations Environment Programme Mediterranean Action Plan vision.
\end{abstract}

\section{LITERATURE CITED}

Agardy, T., and J. Alder. 2005. Coastal systems. Pages 513-550 in R. Hassan, R. Scholes, and N. Ash, editors. Ecosystems and human well-being: current state and trends. Volume 1. Island Press, Washington, D.C., USA.

Angelidis, M. O. 2012. Ecosystem approach for the management of human activities in the Mediterranean. PERSEUS First training school for the promotion and application of EU Environmental Policy Frameworks in non-EU Mediterranean and Black Sea countries, 4-8 June 2012, Chios, Greece. UNEP-MAP, Athens, Greece. [online] URL: http://www.perseus-net.eu/assets/media/ PDF/Chios Training/267.pdf

Artioli, Y., J. Friedrich, A. J. Gilbert, A. Quatters-Gollop, L. D. Mee, J. E. Vermaat, F. Wulff, C. Humborg, L. Palmeri, and F. Pollehne. 2008. Nutrient budgets for European seas: a measure of three ffectiveness of nutrient reduction policies. Marine Pollution Bulletin 56(9):1609-1617. http://dx.doi.org/10.1016/j. marpolbul.2008.05.027

Bainbridge, J. M., T. Potts, and T. G. O’Higgins. 2011. Rapid policy network mapping: a new method for understanding governance structures for implementation of marine environmental policy. Plos ONE 6(10):1-10. http://dx.doi. org/10.1371/journal.pone.0026149

Baltic Marine Environment Protection Commission (HELCOM). 2012. Coordination and information exchange related to the $E U$ $M S F D$ implementation. Joint Advisory Board of the Development of HELCOM Core Set indicators (CORESET)/ Target Review (TARGREV) Projects. HELCOM, Helsinki, Finland.

Barausse, A., A. Duci, C. Mazzoldi, Y. Artioli, and L. Palmeri. 2009. Trophic network model of the Northern Adriatic Sea: analysis of an exploited and eutrophic ecosystem. Estuarine, Coastal and Shelf Science 83(4):577-590. http://dx.doi. org/10.1016/j.ecss.2009.05.003

Barausse, A., A. Michieli, E. Riginella, L. Palmeri, and C. Mazzoldi. 2011. Long-term changes in community composition and life-history traits in a highly exploited basin (northern Adriatic Sea): the role of environment and anthropogenic pressures. Journal of Fish Biology 79(6):1453-1486. http://dx.doi. org/10.1111/j.1095-8649.2011.03139.x

Borja, A., M. Elliot, J. Carstensen, A.-S. Heiskanen, and W. van de Bund. 2010. Marine management-toward an integrated implementation of the European Marine Strategy Framework and the Water Framework Directive. Marine Pollution Bulletin 60 (12):2175-2186. http://dx.doi.org/10.1016/j.marpolbul.2010.09.026

Breton, F., and Z. Skaricic. 2013. PEGASO project. Supporting ICZM in the Mediterranean and the Black Sea Basins. Pages 1-10 in E. Özhan, editor. Global Congress on ICM. Lessons learned to address new challenges. Proceedings of EMECS 10-MEDCOAST 2013 Joint Conference. Volume 1. MEDCOAST Foundation, Ortaca, Turkey.

Cheong, S.-M. 2008. A new direction in coastal management. Marine Policy 32(6):1090-1093. http://dx.doi.org/10.1016/j. marpol.2008.03.004

Cinnirella, S., M. Graziano, J. Pon, C. Murciano, J. Albaigés, and N. Pirrone. 2013. Integrated assessment of chemical pollution in the Mediterranean Sea: driver-pressures-state-welfare analysis. Ocean \& Coastal Management 80:36-45. http://dx.doi. org/10.1016/j.ocecoaman.2013.02.022

Cinnirella, S., D. March, T. O’Higgins, C. Murciano, R. Sardà, J. Albaigés, and N. Pirrone. 2012. A multidisciplinary spatial data infrastructure for the Mediterranean to support the implementation of the Marine Strategy Framework Directive. International Journal of Spatial Data Infrastructure Research 7:323-351. http://dx.doi.org/10.2902/1725-0463.2012.07.art16

Coll, M., C. Piroddi, C. Albouy, F. B. R. Lasram, W. W. L. Cheung, V. Christensen, V. S. Karpouzi, F. Guilhaumon, D. Mouillot, M. Paleczny, M. L. Palomares, J. Steenbeek, P. Trujillo, R. Watson, and D. Pauly. 2012. The Mediterranean Sea under siege: spatial overlap between marine biodiversity, cumulative threats and 
marine reserves. Global Ecology and Biogeography 21(4):465-480. http://dx.doi.org/10.1111/j.1466-8238.2011.00697.x

Coll, M., C. Piroddi, J. Steenbeek, K. Kaschner, F. B. R. Lasram, J. Aguzzi, E. Ballesteros, C. N. Bianchi, J. Corbera, T. Dailianis, R. Danovaro, M. Estrada, C. Froglia, B. S. Galil, J. M. Gasol, R. Gertwage, J. Gil, F. Guilhaumon, K. Kesner-Reyes, M.-S. Kitsos, A. Koukouras, N. Lampadariou, E. Laxamana, C. M. L.-F. de la Cuadra, H. K. Lotze, D. Martin, D. Mouillot, D. Oro, S. Raicevich, J. Rius-Barile, J. I. Saiz-Salinas, C. S. Vicente, S. Somot, J. Templado, X. Turon, D. Vafidis, R. Villanueva, and E. Voultsiadou. 2010. The biodiversity of the Mediterranean Sea: estimates, patterns, and threats. PLOS ONE 5(8):e11842. http:// dx.doi.org/10.1371/journal.pone.0011842

Cooper, P., T. Luisetti, K. Turner, L. G. Kronbak, E. Roth, K. Stobberup, and P. Raux. 2011. KnowSeas-deliverable 4.2 aggregate assessment of benefits and costs. KnowSeas, Oban, Scotland. [online] URL: http://www.msfd.eu/knowseas/library/ D4.2.zip

Cormier, R., A. Kannen, I. M. Davies, R. Sardá, and A. Diedrich. 2013. Policy fragmentation implications in ecosystem-based management in practice. Pages 37-44 in R. Cormier, I. M. Davies, and A. Kannen, editors. Integrated coastal-zone risk management. ICES Cooperative Research Report 320. International Council for the Exploration of the Sea, Copenhagen, Denmark.

Cozzi, S., and M. Giani. 2011. River water and nutrient discharges in the Northern Adriatic Sea: current importance and long term changes. Continental Shelf Research 31(18):1881-1893. http://dx. doi.org/10.1016/j.csr.2011.08.010

Dupont, C., A. Belin, G. Moreira, and B. Vermonden. 2014. Article 12. Technical assessment of the MSFD 2012 obligations. Mediterranean Sea. Milieu Ltd Consortium. European Commission Environment DG, Brussels, Belgium. [online] URL: http://ec.europa.eu/environment/marine/eu-coast-and-marine-policy/ implementation/pdf/regional reports.zip

Ehrlich, P. R., and A. H. Ehrlich. 1981. Extinction: the causes and consequences of the disappearance of species. Random House, New York, New York, USA.

European Commission (EC). 1992. Council directive 92/43/EEC of 21 May 1992 on the conservation of natural habitats and of wild fauna and flora. European Commission, Brussels, Belgium. [online] URL: http://eur-lex.europa.eu/legal-content/EN/TXT/? uri=CELEX:31992L0043

European Commission (EC). 2000. Directive 2000/60/EC of the European Parliament and of the Council of 23 October 2000 establishing a framework for Community action in the field of water policy. European Commission, Brussels, Belgium. [online] URL: http://eur-lex.europa.eu/legal-content/EN/TXT/?uri= CELEX:32000L0060

European Commission (EC). 2001. Directive 2001/42/EC of the European Parliament and of the Council of 27 June 2001 on the assessment of the effects of certain plans and programmes on the environment. European Commission, Brussels, Belgium. [online] URL: http://eur-lex.europa.eu/legal-content/EN/TXT/?uri= CELEX:32001L0042
European Commission (EC). 2008. Directive 2008/56/EC of the European Parliament and of the Council of 17 June 2008 establishing a framework for community action in the field of marine environmental policy (Marine Strategy Framework Directive) (text with EEA relevance). European Commission, Brussels, Belgium. [online] URL: http://eur-lex.europa.eu/legal-content/ EN/TXT/?uri=CELEX:32008L0056

European Commission (EC). 2009a. Directive 2009/147/EC of the European Parliament and of the Council of 30 November 2009 on the conservation of wild birds. European Commission, Brussels, Belgium. [online] URL: http://eur-lex.europa.eu/legal-content/ EN/TXT/?uri=CELEX:32009L0147

European Commission (EC). 2009b. Study of the current status of ratification, implementation and compliance with maritime agreements and conventions applicable to the Mediterranean Sea Basin. With a specific focus on the ENPI South Partner Countries. Regional report. European Commission, EuropeAid Cooperation Office, Brussels, Belgium.

European Commission (EC). 2010. 2010/477/EU: Commission Decision of 1 September 2010 on criteria and methodological standards on good environmental status of marine waters (notified under document C(2010) 5956) (text with EEA relevance). European Commission, Brussels, Belgium. [online] URL: $\underline{\text { http:// }}$ eur-lex.europa.eu/legal-content/EN/TXT/?qid=1416293681156\&uri= CELEX:32010D0477\%2801\%29

European Commission (EC). 2013a.The marine strategy framework directive scoreboard. European Commission, Brussels, Belgium. [online] URL: http://ec.europa.eu/environment/marine/ eu-coast-and-marine-policy/implementation/scoreboard en.htm

European Commission (EC). 2013b. Bluefin tuna (Thunnus thynnus). European Commission, Brussels, Belgium. [online] URL: http://ec.europa.eu/fisheries/marine species/wild species/ bluefin tuna/index en.htm

European Commission (EC). 2013c. Statistics on environmental infringements. European Commission, Brussels, Belgium. [online] URL: http://ec.europa.eu/environment/legal/law/statistics.htm

European Commission (EC). 2014a. Directive 2014/52/EU of the European Parliament and of the Council of 16 April 2014 amending Directive 2011/92/EU on the assessment of the effects of certain public and private projects on the environment (text with EEA relevance). European Commission, Brussels, Belgium. [online] URL: http://eur-lex.europa.eu/legal-content/EN/TXT/?uri= celex:32014L0052

European Commission (EC). 2014b. EU coastal and marine policy. European Commission, Brussels, Belgium. [online] URL: http://ec.europa.eu/environment/marine/eu-coast-and-marine-policy/ index en.htm

European Environment Agency (EEA). 2008. 50 years of protecting Europe's environment. European Environment Agency, Copenhagen, Denmark. [online] URL: http://www.eea.europa. eu/themes/policy/multimedia/50-years-of-protecting-europes-environment/ view

European Parliament. 2002. Recommendation of the European Parliament and of the Council of 30 May 2002 concerning the 
implementation of Integrated Coastal Zone Management in Europe. [online] URL: http://eur-lex.europa.eu/en/index.htm

European Union (EU). 2006. Communication from the Commission to the Council and the European Parliamentestablishing an environment strategy for the Mediterranean $\{$ SEC (2006) 1082$\} / *$ COM/2006/0475 final */. European Union, Brussels, Belgium. [online] URL: http://eur-lex.europa.eu/legalcontent/EN/TXT/?uri=CELEX:52006DC0475

European Union (EU). 2014. Directive adopted by the European Parliament on 17th April, 2014 (European Parliament legislative resolution of 17 April 2014 on the proposal for a directive of the European Parliament and of the Council establishing a framework for maritime spatial planning and integrated coastal maritime spatial planning and integrated coastal management (COM(2013) 0133 - C7-0065/2013 - 2013/0074(COD)) (ordinary legislative procedure: first reading). European Union, Brussels, Belgium.

Farmer, A., L. Mee, O. Langmead, P. Cooper, A. Kannen, P. Kershaw, and V. Cherrier. 2012. The ecosystem approach in marine management. EU FP7 KnowSeas Project. KnowSeas, Oban, Scotland.

Fisher, B., R. K. Turner, and P. Morling. 2009. Defining and classifying ecosystem services for decision making. Ecological Economics 68(3):643-653. http://dx.doi.org/10.1016/j. ecolecon.2008.09.014

Forst, M. F. 2009. The convergence of integrated coastal zone management and the ecosystems approach. Ocean \& Coastal Management 52(6):294-306. http://dx.doi.org/10.1016/j. ocecoaman.2009.03.007

Goulding, I. C., K. A. Stopperup, and T. O’Higgins. 2014. Potential economic impacts of achieving good environmental status in Black Sea fisheries. Ecology and Society 19(3): 32. http:// dx.doi.org/10.5751/ES-06817-190332

Haines-Young, R., and M. Potschin. 2011. Integrated coastal zone management and the ecosystem approach. PEGASO Deliverable D2.1, September 2011. CEM Working Paper No 7. Centre for Environmental Management, University of Nottingham, Nottingham, UK. [online] URL: http://www.nottingham.ac.uk/ CEM/pdf/CEM Working\%20Paper\%207\%20\%281\%29.pdf

Haley, S., L. Chartier, G. Gray, C. Meek, J. Powell, A. Rosenberg, and J. Rosenberg. 2011. Strengthening institutions for stakeholder involvement and ecosystem-based management in the U.S. Arctic offshore. Page 436-457 in A. L. Lovecraft and H. Eicken, editors. North by 2020: perspectives on Alaska's changing social-ecological systems. University of Alaska Press, Fairbanks, Alaska, USA.

Luisetti, T., E. L. Jackson, and R. K. Turner. 2013. Valuing the European 'coastal blue carbon' storage benefit. Marine Pollution Bulletin 71(1-2):101-106. http://dx.doi.org/10.1016/j. marpolbul.2013.03.029

Maccarrone, V., F. Filiciotto, G. Buffa, S. Mazzola, and G. Buscaino. 2014. The ICZM Balanced Scorecard: a tool for putting integrated coastal zone management into action. Marine Policy 44:321-344. http://dx.doi.org/10.1016/j.marpol.2013.09.024

Mozetič, P., C. Solidoro, G. Cossarini, G. Socal, R. Precali, J. Francé, F. Bianchi, C. De Vittor, N. Smodlaka, and S. F. Umani.
2010. Recent trends toward oligotrophication of the Northern Adriatic: evidence from chlorophyll $a$ time series. Estuaries and Coasts 33(2):362-375. http://dx.doi.org/10.1007/s12237-009-9191-7

Mulazzani, L., L. Camanzi, and G. Malorgio. 2012. Price formation and geographic market integration: an empirical investigation of Adriatic small pelagic species. Fisheries Research 119-120:99-107. http://dx.doi.org/10.1016/j.fishres.2011.12.013

O’Higgins, T., P. Cooper, P. Tett, A. Newton, E. Roth, A. Farmer, T. Dolch, J. Friedrich, I. Goulding, J. Icely, C. Murciano, and I. Psuty. 2014b. Temporal constraints on ecosystem management: definitions and examples from Europe's regional seas. Ecology and Society. 19(4): 46. http://dx.doi.org/10.5751/ES-06507-190446

O’Higgins, T., A. Farmer, G. Daskalov, S. Knudsen, and L. Mee. 2014a. Achieving good environmental status in the Black Sea: scale mismatches in environmental management. Ecology and Society 19(3): 54. http://dx.doi.org/10.5751/ES-06707-190354

O'Higgins, T., and E. Roth. 2010. Integrating the common fisheries policy and the marine strategy for the Baltic: discussion of spatial and temporal scales in the management and adaptation to changing climate. Pages 275-294 in G. Schernewski, J. Hofstede, and T. Neumann, editors. Global change and baltic coastal zones. Springer, New York, New York, USA.

Ounanian, K., A. Delaney, J. Raakjær, and P. Ramirez-Monsalve. 2012. On unequal footing: stakeholder perspectives on the marine strategy framework directive as a mechanism of the ecosystembased approach to marine management. Marine Policy 36 (3):658-666. http://dx.doi.org/10.1016/j.marpol.2011.10.008

Palialexis, A., V. Tornero, E. Barbone, D. Gonzalez, G. Hanke, A. C. Cardoso, N. Hoepffner, S. Katsanevakis, F. Somma, and N. Zampoukas. 2013. In-depth assessment of the EU member states' submissions for the Marine Strategy Framework Directive under articles 8, 9 and 10. EUR 26499. Joint Research Centre, Institute for Environment and Sustainability, Ispra, Italy. http://dx.doi. org/10.2788/64014

Partnerships Involving Stakeholders in the Celtic Sea Ecosystem (PISCES). 2014. A guide to implementing the ecosystem approach through the Marine Strategy Framework Directive. Toward sustainability in the Celtic Sea. PICSES, Cardiff, Wales. [online] URL: http://assets.wwf.org.uk/downloads/the pisces guide.pdf

Potts, T., T. O’Higgins, and E. Hastings. 2012. Oceans of opportunity or rough seas? What does the future hold for developments in European marine policy? Philosophical Transactions of the Royal Society A 370:5682-5700. http://dx.doi. org/10.1098/rsta.2012.0394

Potts, T., T. O'Higgins, R. Brennan, S. Cinnirella, U. Steiner Brandt, J. De Vivero, J. Beusekom, T. A. Troost, L. Paltriguera and A. Hosgor. 2015. Detecting critical choke points for achieving Good Environmental Status in European Seas. Ecology and Society, in press Vol. 20 Issue 1.

Sala, E., C. Costello, D. Dougherty, G. Heal, K. Kelleher, J. H. Murray, A. A. Rosenberg, and R. Sumaila. 2013. A general business model for marine reserves. PLoS ONE 8(4):e58799. http://dx.doi.org/10.1371/journal.pone.0058799 
Santojanni, A., N. Cingolani, E. Arneri, A. Belardinelli, G. Giannetti, S. Colella, and F. Donato. 2006. Use of an exploitation rate threshold in the management of anchovy and sardine stocks in the Adriatic Sea. Biologia Marina Mediterranea 13(3):98-111.

Sardá, R. 2013. Ecosystem services in the Mediterranean Sea: the need for an economic and business oriented approach. Pages 1-34 in T. B. Hughes, editor. Mediterranean Sea: ecosystems, economic importance and environmental threats. Nova Science, New York, New York, USA.

Sardá, R., A. Diedrich, J. Tintoré, and R. Cormier. 2011. The ecosystem-based management system: a formal tool for the management of the marine environment. In Littoral 2010. Adapting to global change at the coast: leadership, innovation, and investment 14001. 21-23 September 2010, London, UK. http://dx. doi.org/10.1051/litt/201114001

Suárez de Vivero, J. L. 2012. International treaties in the MED: fisheries cooperation in the Mediterranean and the Black Sea. Note. European Parliament, Directorate-General for Internal Policies, Brussels, Belgium.

Suárez de Vivero, J. L., and J. C. Rodríguez Mateos. 2015. Marine governance in the Mediterranean Sea. In K. Kern and M. Gilek, editors. Governing Europe's marine environment. Europeanization of regional seas or regionalization of EU policies? Ashgate, Surrey, $\mathrm{UK}$, in press.

Tallis, H., P. S. Levin, M. Ruckelshaus, S. E. Lester, K. L. McLeod, D. L. Fluharty, and B. S. Halpern. 2010. The many faces of ecosystem-based management: making the process work today in real places. Marine Policy 34:340-348. http://dx.doi.org/10.1016/ j.marpol.2009.08.003

Trump, D. H. 1980. The prehistory of the Mediterranean [Italian translation by F. Sircana]. Mondadori Editore, Milano, Italy.

United Nations Environmental Program-Mediterranean Action Plan (UNEP-MAP). 1995. SPAMIs. Regional Activity Center for Specially Protected Areas, Tunis, Tunesia. [online] URL: http:// www.rac-spa.org/spami

United Nations Environmental Program-Mediterranean Action Plan (UNEP-MAP). 2008. Annex III. Almeria declaration. 15th Ordinary meeting of the contracting parties to the convention for the protection of the marine environment and the coastal region of the Mediterranean and its protocols. UNEP-MAP, Athens, Greece. [online] URL: http://195.97.36.231/dbases/ acrobatfiles/08IG17_10_Ann3_AlmeriaDeclaration_Eng.pdf

United Nations Environmental Program-Mediterranean Action Plan (UNEP-MAP). 2009. MED POL. UNEP-MAP, Athens, Greece. [online] URL: http://www.unepmap.org/index.php? $\underline{\text { module }}=$ content 2 \&catid $=001017003$

United Nations Environmental Program-Mediterranean Action Plan (UNEP-MAP). 2010. Medwaves. No 59. UNEP-MAP, Athens, Greece.

United Nations Environmental Program-Mediterranean Action Plan (UNEP-MAP). 2012. Report of the 17th ordinary meeting of the contracting parties to the convention for the protection of the marine environment and the coastal region of the Mediterranean and its protocols. Report UNEP(DEPI)/MED IG.20/8. UNEPMAP, Athens, Greece.

United Nations Environmental Program-Mediterranean Action Plan (UNEP-MAP). 2013. Barcelona convention protocols. UNEP-MAP, Athens, Greece.

United Nations Environmental Program-Mediterranean Action Plan-Marine Pollution Assessment And Control Component of MAP (UNEP-MAP-MED POL). 2003. Riverine transport of water, sediments and pollutants to the Mediterranean Sea. MAP Technical Reports Series No. 141. UNEP-MAP, Athens, Greece.

van Hoof, L., and J. van Tatenhove. 2009. EU marine policy on the move: the tension between fisheries and maritime policy. Marine Policy 33(4):726-732. http://dx.doi.org/10.1016/j. marpol.2009.02.007

van Leeuwen, J., L. van Hoof, and J. van Tatenhove. 2012. Institutional ambiguity in implementing the European Union Marine Strategy Framework Directive. Marine Policy 36 (3):636-643. http://dx.doi.org/10.1016/j.marpol.2011.10.007 